\title{
Sleep-Disordered Breathing and Excessive Daytime Sleepiness in Patients With Atrial Fibrillation
}

\author{
Felipe N. Albuquerque, MD; Andrew D. Calvin, MD, MPH; Fatima H. Sert Kuniyoshi, PhD; \\ Tomas Konecny, MD; Francisco Lopez-Jimenez, MD; Gregg S. Pressman, MD; \\ Thomas Kara, MD, PhD; Paul Friedman, MD; Naser Ammash, MD; \\ Virend K. Somers, MD, PhD, FCCP; and Sean M. Caples, DO
}

\begin{abstract}
Background: An important consequence of sleep-disordered breathing (SDB) is excessive daytime sleepiness (EDS). EDS often predicts a favorable response to treatment of SDB, although in the setting of cardiovascular disease, particularly heart failure, SDB and EDS do not reliably correlate. Atrial fibrillation $(\mathrm{AF})$ is another highly prevalent condition strongly associated with SDB. We sought to assess the relationship between EDS and SDB in patients with AF.

Methods: We conducted a prospective study of 151 patients referred for direct current cardioversion for $\mathrm{AF}$ who also underwent sleep evaluation and nocturnal polysomnography. The Epworth Sleepiness Scale (ESS) was administered prior to polysomnography and considered positive if the score was $\geq 11$. The apnea-hypopnea index (AHI) was tested for correlation with the ESS, with a cutoff of $\geq 5$ events/h for the diagnosis of SDB.

Results: Among the study participants, mean age was $69.1 \pm 11.7$ years, mean BMI was $34.1 \pm 8.4 \mathrm{~kg} / \mathrm{m}^{2}$, and $76 \%$ were men. The prevalence of SDB in this population was $81.4 \%$, and $35 \%$ had EDS. The association between ESS score and AHI was low $\left(R^{2}=0.014, P=.64\right)$. The sensitivity and specificity of the ESS for the detection of SDB in patients with AF were $32.2 \%$ and $54.5 \%$, respectively.

Conclusions: Despite a high prevalence of SDB in this population with AF, most patients do not report EDS. Furthermore, EDS does not appear to correlate with severity of SDB or to accurately predict the presence of SDB. Further research is needed to determine whether EDS affects the natural history of AF or modifies the response to SDB treatment.

CHEST 2012; 141(4):967-973

Abbreviations: $\mathrm{AF}=$ atrial fibrillation; $\mathrm{AHI}=$ apnea-hypopnea index; $\mathrm{CPAP}=$ continuous positive airway pressure; CSA = central sleep apnea; DCCV = direct current cardioversion; EDS = excessive daytime sleepiness; OSA = obstructive sleep apnea; $\mathrm{SDB}=$ sleep-disordered breathing
\end{abstract}

S leep-disordered breathing (SDB), collectively encompassed by obstructive sleep apnea (OSA) and central sleep apnea (CSA), is increasingly associated with several common cardiovascular disorders, including hypertension, ${ }^{1}$ heart failure,${ }^{2}$ myocardial infarction, ${ }^{3}$ and atrial fibrillation $(\mathrm{AF}) .^{4} \mathrm{AF}$, the most common sustained arrhythmia that affects $\sim 2.3$ million adults in the United States, ${ }^{5}$ is associated with both OSA and CSA. OSA has been implicated as both a cause of incident $\mathrm{AF}^{4}$ and $\mathrm{AF}$ recurrence after direct current cardioversion (DCCV). ${ }^{6}$ CSA has been shown to be common in samples of patients with AF with and without heart failure. ${ }^{2,7}$ Because OSA appears to be common in patients with $\mathrm{AF}$, affecting approximately one-half of this population, ${ }^{4}$ and may be related to important outcomes, simple screening tools would be useful to guide referral to sleep centers.

An important, although not universal, consequence of SDB is excessive daytime sleepiness (EDS). ${ }^{8} \mathrm{EDS}$ affects $\sim 12 \%$ of the general population..$^{9}$ The mechanisms that lead to EDS in patients with SDB may include nocturnal hypoxia, ${ }^{10}$ repeated arousals from sleep, enhanced sympathetic tone, ${ }^{11}$ or obesity. ${ }^{12}$ EDS is most efficiently detected by the Epworth Sleepiness Scale (ESS), a validated questionnaire that inquires about the chance of dozing under real-life situations. ${ }^{13}$ 
Multiple clinical trials have shown that positive airway pressure therapy effectively improves EDS in patients with OSA. ${ }^{14}$ There is emerging evidence that EDS may be an important predictor of improved cardiovascular outcomes associated with treatment of SDB. ${ }^{15}$ For example, positive airway pressure trials in OSA have shown greater reductions in $\mathrm{BP}$ in those who are sleepy prior to treatment. ${ }^{16,17}$ To further explore this relationship as well as to determine how the ESS performs as a screening tool for SDB in the AF population, we sought to characterize the relationship between EDS and SDB in a cohort of patients with AF.

\section{Materials AND METHODS}

\section{Subjects}

From June 2004 to April 2009 we conducted a prospective study of patients referred to the Mayo Clinic Center for Sleep Medicine for a sleep evaluation following DCCV treatment of AF. A total of 151 patients who underwent in-laboratory-attended polysomnography were included in the analysis. Echocardiography generally was performed prior to DCCV. This study was approved by the Mayo Clinic Institutional Review Board (IRB-\#1646).

\section{Daytime Sleepiness}

To assess the degree of daytime sleepiness, all patients completed the ESS, a simple, self-administered, validated questionnaire used in the general population, ${ }^{13}$ during their initial evaluation prior to the polysomnography. Possible scores ranged from 0 to 24 (the most sleepy); EDS was defined as an ESS score of $\geq 11$. . $^{13}$

Manuscript received April 21, 2011; revision accepted August 5, 2011.

Affiliations: From the Division of Cardiovascular Diseases (Drs Albuquerque, Calvin, Sert Kuniyoshi, Konecny, Lopez-Jimenez, Pressman, Kara, Friedman, Ammash, and Somers) and Division of Pulmonary and Critical Care Medicine (Dr Caples), Mayo Clinic College of Medicine, Mayo Clinic, Rochester, MN; Department of Internal Medicine (Dr Álbuquerque), Hospital of Saint Raphael, Yale University School of Medicine, New Haven, CT; Division of Cardiology (Dr Pressman), Albert Einstein Medical Center, Philadelphia, PA; and ICRC-Department of Cardiovascular Diseases (Dr Kara), St. Anne’s University Hospital, Brno, Czech Republic. Funding/Support: This work was supported by the Mayo Clinic Clinician-Investigator Training Program; Mayo Foundation; American Heart Association [Grant 04-50103Z]; National Heart, Lung, and Blood Institute [Grants HL65176, HL70302, HL73211, and HL099534]; the National Center for Research Resources (NCRR) [Grant 1ULI RR024150], a component of the National Institutes of Health (NIH); IGA of Ministry of Health No. NS10098-4/2008; European Regional Development Fund-Project FNUSA-ICRC [No. CZ.1.05/1.1.00/02.0123]; and the NIH Roadmap for Medical Research.

Correspondence to: Sean M. Caples, DO, Division of Pulmonary and Critical Care Medicine, Mayo Clinic College of Medicine, 200 First St SW, Rochester, MN 55905; e-mail: caples.sean@ mayo.edu

(C) 2012 American College of Chest Physicians. Reproduction of this article is prohibited without written permission from the American College of Chest Physicians (http://www.chestpubs.org/ site/misc/reprints.xhtml)

DOI: 10.1378/chest.11-0975

\section{Polysomnography}

The diagnosis of SDB was established by attended polysomnography performed at the Mayo Clinic Center for Sleep Medicine and digitally recorded by a multichannel system (Nicolet Instrument Corp). We used an apnea-hypopnea index (AHI) cutoff of $\geq 5$ events/h to diagnose SDB. Simultaneously recorded parameters included three-channel EEG, two-channel electrooculography, oronasal airflow by pressure transducer and thermocouple sensors, submental and limb electromyograms, ECG, transcutaneous pulse oximetry (Ohmeda 3740; GE Healthcare), thoracic and abdominal respiratory effort by inductance plethysmography, snoring by external microphone, and body position by closed-circuit video monitoring.

Scoring of sleep stages, disordered breathing events, oxygen desaturation, and periodic limb movement was performed by an experienced polysomnographic technician, and results were reviewed by a board certified physician in accordance with current American Academy of Sleep Medicine guidelines. Apneas were defined as cessation of airflow or a $>90 \%$ reduction of airflow from baseline for $\geq 10 \mathrm{~s}$. Hypopneas were defined as a reduction in airflow of $\geq 50 \%$ for $\geq 10 \mathrm{~s}$ followed by an oxygen desaturation of $\geq 4 \%$. Events were classified as central when the airflow criteria were met in the absence of respiratory effort as recorded by thoracic and abdominal inductance plethysmography and as obstructive when airflow criteria were met despite continued or increased respiratory effort. After classification, disordered breathing events were quantified by the AHI and reported as the mean number of events per hour. Subjects were considered to have CSA if the total AHI was $\geq 5$ events/h with $\geq 50 \%$ of disordered breathing events classified as of central origin or with classic Cheyne-Stokes pattern of respiration. Oxygen saturation was measured prior to and continuously during sleep and quantified by both the mean oxygen saturation and the proportion of sleep time spent with arterial oxygen saturation $>90 \%$.

\section{Statistical Analysis}

Data are summarized as frequencies for categorical variables and mean \pm SEM for continuous variables, unless otherwise noted. Group differences were evaluated by two-sided $t$ test or Wilcoxon rank sum test, depending on distribution. Differences in proportions were tested by Fisher exact test. The ESS score also was treated as a continuous variable for data exploration.

Patients were stratified by different AHI cutoffs as having no SDB ( $<5$ events/h), mild SDB ( $\geq 5$ - 15 events/h), moderate SDB (>15-30 events/h), or severe SDB (> 30 events/h) (Fig 1$)$, and

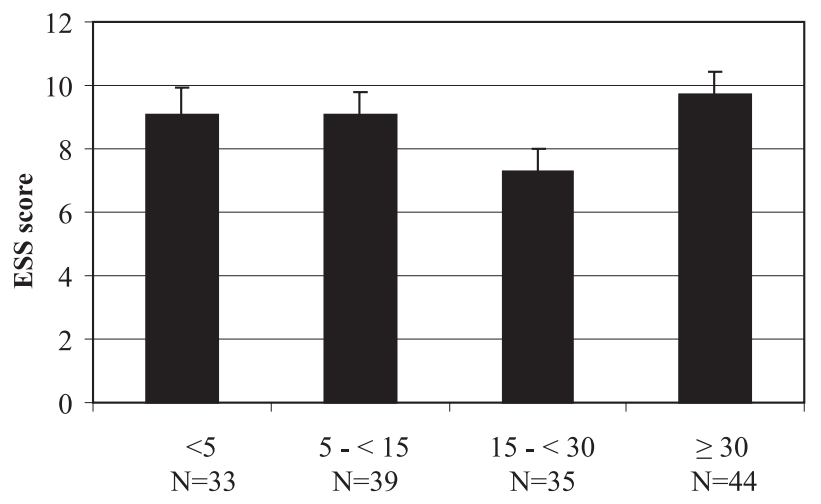

AHI (Events/h)

Figure 1. Mean ESS score of the population divided into different AHI cutoffs. AHI = apnea-hypopnea index; ESS = Epworth Sleepiness Scale. 
Table 1-Subject Characteristics

\begin{tabular}{|c|c|c|c|}
\hline Characteristic & No $\operatorname{EDS}(\mathrm{n}=98)$ & $\operatorname{EDS}(\mathrm{n}=53)$ & $P$ Value \\
\hline Age, y & $70.1 \pm 1.2$ & $67.1 \pm 1.6$ & .13 \\
\hline Male sex & 80.6 & 68.8 & .08 \\
\hline $\mathrm{BMI}, \mathrm{kg} / \mathrm{m}^{2}$ & $33.6 \pm 0.8$ & $35.0 \pm 1.1$ & .31 \\
\hline Ejection fraction, $\%$ & $53.9 \pm 1.3$ & $57.8 \pm 1.8$ & .08 \\
\hline Ejection fraction $\leq 40 \%$ & 16.3 & 9.4 & .24 \\
\hline LV diastolic dimension, $\mathrm{mm}$ & $52.4 \pm 0.7$ & $52.4 \pm 0.9$ & .97 \\
\hline LV systolic dimension, mm & $36.3 \pm 0.9$ & $34.9 \pm 1.1$ & .33 \\
\hline RV systolic pressure, $\mathrm{mm} \mathrm{Hg}$ & $39.2 \pm 1.7$ & $42.3 \pm 2.3$ & .28 \\
\hline RA pressure, $\mathrm{mm} \mathrm{Hg}$ & $8.5 \pm 0.5$ & $8.7 \pm 0.7$ & .81 \\
\hline
\end{tabular}

Data are presented as mean $\pm \mathrm{SE}$ or $\% . \mathrm{EDS}=$ excessive daytime sleepiness; $\mathrm{LV}=$ left ventricle; $\mathrm{RA}=$ right atrium; $\mathrm{RV}=$ right ventricle.

the mean ESS was compared between these groups by analysis of variance. The sensitivity, specificity, positive predictive value, and negative predictive value of the ESS using cutoffs within the interquartile range of the ESS score distribution were calculated for prediction of SDB ( $\geq 5$ events/h). Linear regression analysis was used to assess the association between AHI and ESS. The sensitivity, specificity, positive predictive value, and negative predictive value were used to evaluate the ability of an ESS score $\geq 11$ to predict SDB using various AHI cutoffs. As a secondary analysis, the sensitivity, specificity, positive predictive value, and negative predictive value of the ESS using the conventional cutoff of $\geq 11$ to predict SDB ( $\geq 5$ events/h) were compared among men and women and in subjects aged $\geq 70$ and $<70$ years using logistic regression to test for a significant interaction. Analyses were performed with JMP, version 7 (SAS Institute Inc) statistical software. For all comparisons $P<.05$ was considered statistically significant.

\section{RESUlTS}

Demographic characteristics of all subjects according to the presence or absence of EDS are reported in Table 1 . Mean age was $69.1 \pm 0.9$ years, mean BMI was $34.1 \pm 0.7 \mathrm{~kg} / \mathrm{m}^{2}$, and $76 \%$ of the patients were men. The mean left ventricular ejection fraction was $55.3 \% \pm 1.1 \%$; only $14 \%$ of the subjects had a left ventricular ejection fraction of $\leq 40 \%$. The overall prevalence of SDB was $81.4 \%$. OSA, as defined by an AHI of $\geq 5$ events/h, was present in $57 \%$ of the subjects; using an AHI cutoff of $\geq 15$ events/h, the prevalence was $52.3 \%$. Additionally, $13.9 \%$ of the patients had CSA, $10.6 \%$ had mixed sleep apnea, and $18.6 \%$ had normal polysomnography (Table 2). $\mathrm{SDB}$ was more common in men than in women $(87.8 \%$ vs $61.1 \%, P<.001)$. The mean AHI was $23.1 \pm 1.8$ events/h in the whole population and $27.4 \pm 2.0$ events/h in those with SDB. On average, women had a lower mean AHI compared with men in the entire sample $(15.5 \pm 3.7$ events/h vs $25.5 \pm$ 2.0 events/h, $P=.02$ ) and among those with SDB $(21.1 \pm 3.8$ events/h vs $28.8 \pm 2.3$ events/h, $P=.09$ ).

EDS was present in $35 \%$ of all subjects and did not differ by the presence or absence of SDB (31.3\% vs $47.2 \%, P=.08$ ) or among those with OSA, CSA, and mixed apnea ( $37.2 \%$ vs $19.1 \%$ vs $25.0 \%, P=.34$ ). The correlation of total AHI and the ESS score was very low $\left(R^{2}<0.01, P=.64\right)$. The mean ESS score was $8.9 \pm 0.36$ and did not differ by the presence or absence of $\mathrm{SDB}(8.9 \pm 0.4$ vs $9.0 \pm 0.8, P=.8)$ or

Table 2_Polysomnographic Findings of Patients With and Without EDS

\begin{tabular}{|c|c|c|c|}
\hline Characteristic & No $\operatorname{EDS}(\mathrm{n}=98)$ & $\operatorname{EDS}(\mathrm{n}=53)$ & $P$ Value \\
\hline AHI, events/h & $23.5 \pm 2.3$ & $22.3 \pm 3.1$ & .75 \\
\hline OSA & $32(62.8)$ & $21(37.2)$ & .53 \\
\hline CSA & $17(80.9)$ & $4(19.1)$ & .10 \\
\hline Mixed & $12(75.0)$ & $4(25.0)$ & .37 \\
\hline Normal PSG & $15(53.6)$ & $13(46.4)$ & .19 \\
\hline Total sleep time, min & $180 \pm 8.5$ & $194 \pm 11.6$ & .33 \\
\hline Sleep efficiency, $\%$ & $68.4 \pm 1.6$ & $74.7 \pm 2.2$ & .03 \\
\hline$\%$ Total sleep time $>90 \% \mathrm{SaO}_{2}$ & $88.0 \pm 2.3$ & $83.6 \pm 3.1$ & .23 \\
\hline$\%$ Total sleep time stage 1 & $18.45 \pm 1.5$ & $18.45 \pm 2.1$ & .99 \\
\hline$\%$ Total sleep time stage 2 & $54.7 \pm 1.6$ & $54.5 \pm 2.1$ & .94 \\
\hline$\%$ Total sleep time stage $3 / 4$ & $14.9 \pm 1.4$ & $15.9 \pm 1.9$ & .68 \\
\hline \% Total sleep time stage REM & $11.9 \pm 0.9$ & $11.1 \pm 1.3$ & .62 \\
\hline $\mathrm{AHI}<5(\mathrm{n}=33)$ & 54.6 & 45.4 & .15 \\
\hline $5 \leq \mathrm{AHI}<15(\mathrm{n}=39)$ & 61.5 & 38.5 & .6 \\
\hline $15 \leq \mathrm{AHI}<30(\mathrm{n}=35)$ & 85.7 & 14.3 & $<.01$ \\
\hline $\mathrm{AHI} \geq 30(\mathrm{n}=44)$ & 59 & 41 & .33 \\
\hline
\end{tabular}

Data are presented as mean \pm SE, No. $(\%)$, or \%. AHI = apnea-hypopnea index; CSA = central sleep apnea; OSA = obstructive sleep apnea; $\mathrm{PSG}=$ polysomnogram; $\mathrm{REM}=$ rapid eye movement; $\mathrm{SaO}_{2}=$ arterial oxygen saturation. See Table 1 legend for expansion of other abbreviation. 
Table 3-ESS Scores and Prevalence of EDS Using Different AHI Cutoffs

\begin{tabular}{|c|c|c|c|c|c|}
\hline & $\mathrm{AHI}<5$ & $5 \leq \mathrm{AHI}<15$ & $15 \leq \mathrm{AHI}<30$ & $\mathrm{AHI} \geq 30$ & $P$ Value \\
\hline ESS score, mean $\pm \mathrm{SE}$ & $9.2 \pm 0.8$ & $9.2 \pm 0.7$ & $7.3 \pm 0.8$ & $9.7 \pm 0.7$ & .12 \\
\hline ESS score $\geq 11, \%$ & 28.3 & 28.3 & 9.4 & 34.0 & .03 \\
\hline
\end{tabular}

ESS $=$ Epworth Sleepiness Scale. See Table 1 and 2 legends for expansion of other abbreviations.

severity of SDB (no SBD, 9.2 \pm 0.8 ; mild, 9.2 \pm 0.7 ; moderate, $7.3 \pm 0.8$; severe, $9.7 \pm 0.7 ; P=.12$ ). Mean ESS did not differ between men and women in the entire study ( 8.7 vs $9.5, P=.38$ ) or between men and women with $\mathrm{SDB}(8.7 \pm 0.4$ vs $9.4 \pm 1.0, P=.60)$. The percentage of subjects with an ESS score $\geq 11$ showed a significant $(P=.03)$, although nonlinear trend (Table 3). The interquartile range of ESS scores was 5 to 12, and no ESS cutoff in this range appeared to function better than the standard cutoff of 11 (Table 4).

There was no significant difference in the mean AHI in patients with EDS compared with patients without EDS $(22.3 \pm 3.1$ vs $23.5 \pm 2.3, P=.75)$. Using an AHI cutoff of $\geq 5$ events/h to diagnose SDB, the sensitivity and specificity of the ESS score to predict SDB were $32.2 \%$ and $54.5 \%$, respectively, with a positive predictive value of $71.7 \%$ and negative predictive value of $18.8 \%$; similar results were obtained using different AHI cutoffs (Table 5). The prevalence of EDS in patients with OSA $(\mathrm{n}=86)$ was $\sim 37 \%$, and in patients with CSA $(n=21)$, it was $19 \%$. Excluding all the patients with heart failure $(n=21)$, the prevalence of EDS slightly increased from $35 \%$ to $37 \%$. No significant interaction was seen between the ESS and sex $(P=.66)$ or age $(P=.18)$, although the ESS showed a trend toward higher sensitivity in women and subjects aged $\geq 70$ years and greater specificity in men and subjects aged $<70$ years (Table 6 ).

\section{DISCUSSION}

The present study demonstrates that SDB is highly prevalent in patients with AF referred for sleep evaluation following DCCV who, despite marked elevations in the AHI, generally do not report subjective daytime sleepiness. Furthermore, EDS does not correlate with the presence or absence of SDB. Given the very high prevalence of $\mathrm{SDB}$ in patients with $\mathrm{AF}$, the lack of sleepiness cannot be used to rule out the presence of SDB.

The data suggest that typical symptoms such as EDS cannot be relied on as a marker of SDB in the AF population. Although the main results show a low sensitivity (32.2\%) and specificity $(54.5 \%)$ of the ESS using the standard AHI cutoff of 5 events/h for the diagnosis of SDB, similar results were obtained using a higher AHI cutoff of 15 events/h (sensitivity, 29.1\%; specificity, 50.0\%). Furthermore, using different cutoff values did not seem to significantly improve the performance of the ESS, nor did the ESS perform significantly better in men vs women or in older vs younger adults. These results suggest that clinicians should not exclude the possibility of SDB in patients with $\mathrm{AF}$ who do not have sleep-related complaints. A similar relationship has been reported in the heart failure and stroke population with SDB, where patients appear to infrequently report subjective sleepiness. ${ }^{18,19}$ It has been speculated that the lack of sleepiness in patients with heart failure may be linked with increased sympathetic nervous activity. ${ }^{20}$ Because heightened sympathetic tone has been associated with $\mathrm{AF},{ }^{21}$ a similar mechanism may be involved in patients with $\mathrm{AF}$.

A key question that remains to be clarified is whether these findings play a role in important outcomes in the AF population. Potential clues can be found from the literature describing other cardiovascular diseases. For example, there is evidence that the association between SDB and hypertension is stronger in patients

Table 4-Performance of the ESS for SDB

\begin{tabular}{llcr}
\hline \hline ESS Score & Sensitivity, $\%$ & Specificity, $\%$ & PPV, $\%$ \\
\hline 5 & $82.1(74.4-87.9)$ & $14.3(5.7-31.5)$ & $80.8(73.0-86.7)$ \\
6 & $73.2(64.7-80.2)$ & $21.4(10.2-39.5)$ & $80.4(72.0-86.7)$ \\
7 & $65.0(56.3-72.9)$ & $32.1(17.9-50.7)$ & $80.8(72.0-87.4)$ \\
8 & $54.5(45.7-63.0)$ & $42.9(26.5-60.9)$ & $80.7(71.0-87.8)$ \\
9 & $46.3(37.8-55.1)$ & $46.4(29.5-64.2)$ & $79.2(68.4-86.9)$ \\
10 & $39.0(30.9-47.9)$ & $46.4(29.5-64.2)$ & $76.2(64.4-85.0)$ \\
11 & $32.5(24.9-41.2)$ & $53.6(35.8-70.5)$ & $75.5(62.4-85.1)$ \\
12 & $29.3(22.0-37.8)$ & $67.9(49.3-82.1)$ & $17.6(10.4-29.7)$ \\
\hline
\end{tabular}

Data are presented as median (95\% CI). SDB was defined as an AHI $\geq 5$ events/h. NPV = negative predictive value; PPV $=$ positive predictive value; SDP = sleep-disordered breathing. See Table 2 and 3 legends for expansion of other abbreviations. 
Table 5-Accuracy of the ESS as a Predictor of SDB

\begin{tabular}{lcccr}
\hline \hline AHI, Events/h & Sensitivity, $\%$ & Specificity, $\%$ & PPV, $\%$ & NPV, $\%$ \\
\hline$\geq 5$ & $32.2(24.4-41.1)$ & $54.5(38.0-70.2)$ & $71.7(58.4-82.0)$ & $18.4(11.9-27.2)$ \\
$\geq 10$ & $27.7(19.6-37.4)$ & $52.6(39.9-65.0)$ & $49.1(36.1-62.1)$ & $30.6(22.4-40.3)$ \\
$\geq 15$ & $29.1(20.3-39.9)$ & $58.3(46.8-69.0)$ & $43.4(31.0-56.7)$ & $42.9(33.5-52.7)$ \\
$\geq 30$ & $40.9(27.7-55.6)$ & $67.3(57.9-75.4)$ & $34.0(22.7-47.4)$ & $73.5(64.0-81.2)$ \\
\hline
\end{tabular}

Data are presented as median (95\% CI). See Table 2, 3, and 4 legends for expansion of abbreviations.

who report sleepiness than in those who do not. ${ }^{15}$ Furthermore, data from controlled interventional trials suggest that subjects who are less sleepy show a smaller decrease in $\mathrm{BP}$ with continuous positive airway pressure (CPAP). ${ }^{22,23}$ In a previous observational study, our laboratory reported that compliance with prescribed CPAP therapy for sleep apnea favorably alters the natural history of $\mathrm{AF}$ following electric cardioversion. ${ }^{6}$ It is acknowledged that symptoms such as EDS likely promote compliance with CPAP therapy, ${ }^{24,25}$ which may, therefore, lead to more complete eradication of the downstream effects of apnea. Further research is needed to determine whether EDS is an important modifier of cardiovascular outcomes in this population.

The present study confirms previous data showing a high prevalence of sleep apnea in patients with AF. 4,7,26 The fact that many do not have sleep-related complaints raises the question of how to manage such patients. As noted previously, some data suggest that there is little evidence showing that CPAP treatment affects cardiovascular outcomes in patients who are not sleepy. Furthermore, a significant portion of older adults may have an AHI $>5$ events $/ \mathrm{h} .{ }^{27}$ On the other hand, it is difficult to ignore the public health problem of $\mathrm{AF}$, which is associated with complications such as stroke, heart failure, and death. ${ }^{28}$ We have shown that patients with OSA who are successfully cardioverted but do not receive CPAP treatment may be at a twofold greater risk for recurrence of $\mathrm{AF}$ within 1 year. ${ }^{6}$ Conceivably, recognition and treatment of SDB may directly affect maintenance of sinus rhythm and influence the likelihood of complications.

Further considerations include the logistics of identifying, diagnosing, and treating SDB in the AF population. Screening tools in SDB are not well standardized, and the use of questionnaires and nocturnal pulse oximetry are controversial. Snoring is very common but an insensitive marker of OSA. ${ }^{29}$ EDS often has been used as a potential marker for the presence of undiagnosed sleep apnea. However, the present data suggest that EDS does not provide a valid indication of the presence or absence of occult sleep apnea. The role of screening tools in this patient population requires further study and validation. Furthermore, commonly used questionnaires suggesting the presence of sleep apnea should exclude the use of sleepiness as a scored variable because inclusion of this measure in any index would likely diminish the sensitivity and specificity of the overall index for patients with $\mathrm{AF}$ undergoing cardioversion.

The present findings have some limitations. The ESS questionnaire is considered to be a marker of subjective sleepiness, and we acknowledge its limited correlation with objective measures of sleepiness, such as the multiple sleep latency test. ${ }^{30}$ In addition, its validity in a strictly referral population with cardiovascular disease is not entirely known. As a comparison, the prevalence of EDS in this sample exceeds estimates from population-based studies showing that $15 \%$ to $20 \%$ of persons in the community will score $>10$ on the ESS. ${ }^{31}$ Selection bias may have resulted in a higher prevalence of SDB than in the general population of patients with AF because our population was referred for sleep evaluation following DCCV. Finally, none of the patients were found to have other potential causes of EDS, such as narcolepsy, periodic limb movement disorder, and the idiopathic hypersomnia syndromes.

In summary, among patients with AF referred for cardioversion, there is a high prevalence of SDB,

Table 6-Accuracy of the ESS as a Predictor of SDB in Different Subgroups

\begin{tabular}{lccccc}
\hline \hline Subgroup & Sensitivity, $\%$ & Specificity, $\%$ & PPV, \% & NPV, \% & P Interaction \\
\hline Overall & $32.5(24.9-41.2)$ & $53.6(35.8-70.5)$ & $75.5(62.4-85.1)$ & $15.3(9.5-23.7)$ & $\ldots .1(5.2-18.7)$ \\
Men & $29.7(21.7-39.2)$ & $57.1(32.6-78.6)$ & $83.3(68.1-92.1)$ & $36.8(19.1-59.0)$ & .66 \\
Women & $45.5(26.9-65.3)$ & $50.0(26.8-73.2)$ & $58.8(36.0-78.4)$ & $\ldots$ \\
Aged $<70$ y & $40.7(28.7-54.0)$ & $57.9(36.3-76.9)$ & $73.3(55.6-85.8)$ & $25.6(14.9-40.2)$ & .18 \\
Aged $\geq 70$ y & $73.3(55.6-85.8)$ & $25.6(14.9-40.2)$ & $40.7(28.7-54.0)$ & $57.9(36.3-76.9)$ & $\ldots$ \\
\hline
\end{tabular}

Data are presented as median $(95 \% \mathrm{CI})$. A positive ESS was considered to be a score of $\geq 11$, and SDB was defined as an AHI $\geq 5$ events/h. See Table 2, 3, and 4 legends for expansion of abbreviations. 
although most patients do not report EDS as measured by the ESS. Furthermore, EDS does not appear to correlate with severity of the SDB or to accurately predict the presence or absence of SDB in patients with AF. Further research is needed to determine whether EDS affects the natural history of AF or modifies the response to treatment of $\mathrm{AF}$ or SDB in this population.

\section{ACKNOWLEDGMENTS}

Author contributions: Drs Albuquerque, Calvin, Sert Kuniyoshi, Somers, and Caples had full access to all of the data in the study and takes responsibility for the integrity of the data and the accuracy of the data analysis.

Dr Albuquerque: contributed to the study concept and design; data acquisition, interpretation, and analysis; drafting of the manuscript; and critical revision of the manuscript.

Dr Calvin: contributed to the study concept and design; data acquisition, interpretation, and analysis; drafting of the manuscript; and critical revision of the manuscript.

Dr Sert Kuniyoshi: contributed to the study concept and design; data acquisition, interpretation, and analysis; drafting of the manuscript; and critical revision of the manuscript.

Dr Konecny: contributed to the data interpretation and analysis, drafting of the manuscript, and critical revision of the manuscript.

Dr Lopez-Jimenez: contributed to the study concept and design, data interpretation and analysis, drafting of the manuscript, and critical revision of the manuscript.

Dr Pressman: contributed to the data interpretation and analysis, drafting of the manuscript, and critical revision of the manuscript.

Dr Kara: contributed to the drafting of the manuscript and critical revision of the manuscript.

Dr Friedman: contributed to the drafting of the manuscript and critical revision of the manuscript.

Dr Ammash: contributed to the drafting of the manuscript and critical revision of the manuscript.

Dr Somers: contributed to the study concept and design, data interpretation and analysis, drafting of the manuscript, and critical revision of the manuscript.

Dr Caples: contributed to the study concept and design; data acquisition, interpretation, and analysis; drafting of the manuscript; and critical revision of the manuscript.

Financial/nonfinancial disclosures: The authors have reported to CHEST the following conflicts of interest: Dr Sert Kuniyoshi became a full-time employee for Philips Respironics Inc after the collection of the data provided in this article. Dr Pressman has received research grant support from Phillips Respironics Inc. Dr Friedman has been an investigator or coinvestigator on research grants funded by Medtronic, Inc, and Pfizer, Inc, and has served as a consultant to Medtronic, Inc; Boston Scientific Corporation; St. Jude Medical, Inc; and C. R. Bard, Inc. Dr Somers has served as a consultant for Respironics Inc; ResMed Corp; Cardiac Concepts, Inc; GlaxoSmithKline plc; Sepracor; and Medtronic, Inc, and has been a principal investigator or coinvestigator on research grants funded by the Respironics Foundation, the ResMed Foundation, and the Sorin Corporation. Dr Caples has received research support from the ResMed Foundation; Ventus Medical, Inc; and Restore Medical, Inc. Drs Albuquerque, Calvin, Konecny, Lopez-Jimenez, Kara, and Ammash have reported that no potential conflicts of interest exist with any companies/organizations whose products or services may be discussed in this article.

Role of sponsors: This article and its content are solely the responsibility of the authors and do not necessarily represent the official view of NCRR or NIH. The sponsor had no role in the design of the study, the collection and analysis of the data, or in the preparation of the manuscript.

Other contributions: This work was performed at the Mayo Clinic (Rochester, Minnesota). We thank Aynur Okcay, MD, and Ivani Trombetta, PhD, for their significant contribution to the manuscript.

\section{REFERENCES}

1. Nieto FJ, Young TB, Lind BK, et al. Association of sleepdisordered breathing, sleep apnea, and hypertension in a large community-based study. Sleep Heart Health Study. JAMA. 2000;283(14):1829-1836.

2. Javaheri S, Parker TJ, Liming JD, et al. Sleep apnea in 81 ambulatory male patients with stable heart failure. Types and their prevalences, consequences, and presentations. Circulation. 1998;97(21):2154-2159.

3. Sert Kuniyoshi FH, Garcia-Touchard A, Gami AS, et al. Day-night variation of acute myocardial infarction in obstructive sleep apnea. J Am Coll Cardiol. 2008;52(5):343-346.

4. Gami AS, Pressman G, Caples SM, et al. Association of atrial fibrillation and obstructive sleep apnea. Circulation. 2004; 110(4):364-367.

5. Go AS, Hylek EM, Phillips KA, et al. Prevalence of diagnosed atrial fibrillation in adults: national implications for rhythm management and stroke prevention: the AnTicoagulation and Risk Factors in Atrial Fibrillation (ATRIA) Study. JAMA. 2001;285(18):2370-2375.

6. Kanagala R, Murali NS, Friedman PA, et al. Obstructive sleep apnea and the recurrence of atrial fibrillation. Circulation. 2003;107(20):2589-2594.

7. Sin DD, Fitzgerald F, Parker JD, Newton G, Floras JS, Bradley TD. Risk factors for central and obstructive sleep apnea in 450 men and women with congestive heart failure. Am J Respir Crit Care Med. 1999;160(4):1101-1106.

8. Gottlieb DJ, Whitney CW, Bonekat WH, et al. Relation of sleepiness to respiratory disturbance index: the Sleep Heart Health Study. Am J Respir Crit Care Med. 1999;159(2):502-507.

9. Klink ME, Sethi GK, Copeland JG, Quan SF. Obstructive sleep apnea in heart transplant patients. A report of five cases. Chest. 1993;104(4):1090-1092.

10. BaHammam A. Excessive daytime sleepiness in patients with sleep-disordered breathing. Eur Respir J. 2008;31(3):685-686.

11. Lombardi C, Parati G, Cortelli P, et al. Daytime sleepiness and neural cardiac modulation in sleep-related breathing disorders. J Sleep Res. 2008;17(3):263-270.

12. Vgontzas AN, Bixler EO, Tan TL, Kantner D, Martin LF, Kales A. Obesity without sleep apnea is associated with daytime sleepiness. Arch Intern Med. 1998;158(12):1333-1337.

13. Johns MW. A new method for measuring daytime sleepiness: the Epworth sleepiness scale. Sleep. 1991;14(6):540-545.

14. Patel SR, White DP, Malhotra A, Stanchina ML, Ayas NT. Continuous positive airway pressure therapy for treating sleepiness in a diverse population with obstructive sleep apnea: results of a meta-analysis. Arch Intern Med. 2003;163(5):565-571.

15. Kapur VK, Resnick HE, Gottlieb DJ; Sleep Heart Health Study Group. Sleep disordered breathing and hypertension: does self-reported sleepiness modify the association? Sleep. 2008;31(8):1127-1132.

16. Robinson GV, Smith DM, Langford BA, Davies RJ, Stradling JR. Continuous positive airway pressure does not reduce blood pressure in nonsleepy hypertensive OSA patients. Eur Respir J. 2006;27(6):1229-1235.

17. Pepperell JC, Maskell NA, Jones DR, et al. A randomized controlled trial of adaptive ventilation for Cheyne-Stokes breathing in heart failure. Am J Respir Crit Care Med. 2003; 168(9):1109-1114.

18. Arzt M, Young T, Finn L, et al. Sleepiness and sleep in patients with both systolic heart failure and obstructive sleep apnea. Arch Intern Med. 2006;166(16):1716-1722.

19. Arzt M, Young T, Peppard PE, et al. Dissociation of obstructive sleep apnea from hypersomnolence and obesity in patients with stroke. Stroke. 2010;41(3):e129-e134.

20. Leimbach WN Jr, Wallin BG, Victor RG, Aylward PE, Sundlöf G, Mark AL. Direct evidence from intraneural 
recordings for increased central sympathetic outflow in patients with heart failure. Circulation. 1986;73(5):913-919.

21. Wasmund SL, Li JM, Page RL, et al. Effect of atrial fibrillation and an irregular ventricular response on sympathetic nerve activity in human subjects. Circulation. 2003;107(15): 2011-2015.

22. Robinson GV, Pepperell JC, Segal HC, Davies RJ, Stradling JR. Circulating cardiovascular risk factors in obstructive sleep apnoea: data from randomised controlled trials. Thorax. 2004;59(9):777-782.

23. Barbé F, Mayoralas LR, Duran J, et al. Treatment with continuous positive airway pressure is not effective in patients with sleep apnea but no daytime sleepiness. a randomized, controlled trial. Ann Intern Med. 2001;134(11):1015-1023.

24. Hoffstein V, Viner S, Mateika S, Conway J. Treatment of obstructive sleep apnea with nasal continuous positive airway ressure. Patient compliance, perception of benefits, and side effects. Am Rev Respir Dis. 1992;145(4 pt 1):841-845.

25. Rolfe I, Olson LG, Saunders NA. Long-term acceptance of continuous positive airway pressure in obstructive sleep apnea. Am Rev Respir Dis. 1991;144(5):1130-1133.
26. Gami AS, Hodge DO, Herges RM, et al. Obstructive sleep apnea, obesity, and the risk of incident atrial fibrillation. J Am Coll Cardiol. 2007;49(5):565-571.

27. Young T, Shahar E, Nieto FJ, et al; Sleep Heart Health Study Research Group. Predictors of sleep-disordered breathing in community-dwelling adults: the Sleep Heart Health Study. Arch Intern Med. 2002;162(8):893-900.

28. Benjamin EJ, Wolf PA, D'Agostino RB, Silbershatz H, Kannel WB, Levy D. Impact of atrial fibrillation on the risk of death: the Framingham Heart Study. Circulation. 1998;98(10):946-952

29. Exar EN, Collop NA. The upper airway resistance syndrome. Chest. 1999;115(4):1127-1139.

30. Carskadon MA, Dement WC, Mitler MM, Roth T, Westbrook PR, Keenan S. Guidelines for the multiple sleep latency test (MSLT): a standard measure of sleepiness. Sleep. 1986;9(4):519-524.

31. Pallesen S, Nordhus IH, Omvik S, Sivertsen B, Tell GS, Bjorvatn B. Prevalence and risk factors of subjective sleepiness in the general adult population. Sleep. 2007;30(5): 619-624. 